\title{
Development, Investigation, and Comparative Study of the Effects of Various Metal Oxides on Optical Electrochemical Properties Using a Doped PANI Matrix
}

\author{
Amina Bekhoukh ${ }^{1}$, Imane Moulefera ${ }^{1,2}$, Lilia Sabantina ${ }^{3}$ iD and Abdelghani Benyoucef $^{1, *(D)}$ \\ 1 L.M.A.E. Laboratory, Faculty of Science and Technology, University of Mustapha Stambouli Mascara, \\ Mascara 29000, Algeria; amina.bekhoukh@univ-mascara.dz (A.B.); imanemoulefera@yahoo.fr (I.M.) \\ 2 Department of Chemical Engineering, Faculty of Science, University of Málaga, Andalucía TECH, \\ 29071 Málaga, Spain \\ 3 Junior Research Group "Nanomaterials", Faculty of Engineering and Mathematics, Bielefeld University of \\ Applied Sciences, 33619 Bielefeld, Germany; lilia.sabantina@fh-bielefeld.de \\ * Correspondence: a.benyoucel@univ-mascara.dz
}

\section{check for}

updates

Citation: Bekhoukh, A.; Moulefera, I.; Sabantina, L.; Benyoucef, A. Development, Investigation, and Comparative Study of the Effects of Various Metal Oxides on Optical Electrochemical Properties Using a Doped PANI Matrix. Polymers 2021 13, 3344. https://doi.org/10.3390/ polym13193344

Academic Editor: Arunas

Ramanavicius

Received: 21 August 2021

Accepted: 26 September 2021

Published: 29 September 2021

Publisher's Note: MDPI stays neutral with regard to jurisdictional claims in published maps and institutional affiliations.

Copyright: (c) 2021 by the authors. Licensee MDPI, Basel, Switzerland. This article is an open access article distributed under the terms and conditions of the Creative Commons Attribution (CC BY) license (https:// creativecommons.org/licenses/by/ $4.0 /)$.
Abstract: A comparative study was performed in order to analyze the effect of metal oxide (MO) on the properties of a polymeric matrix. In this study, polyaniline (PANI)@ $\mathrm{Al}_{2} \mathrm{O}_{3}$, PANI@TiC, and $\mathrm{PANI} @ \mathrm{TiO}_{2}$ nanocomposites were synthesized using in situ polymerization with ammonium persulfate as an oxidant. The prepared materials were characterized by various analytical methods such as X-ray photoelectron spectroscopy (XPS), X-ray diffraction (XRD), thermogravimetric analysis (TGA), UV/visible (UV/Vis) spectroscopy, Fourier-transform infrared spectroscopy (FTIR), and transmission electron microscopy (TEM). Furthermore, the conductive properties of the materials were tested using the four-point probe method. The presence of $\mathrm{MO}$ in the final product was confirmed by XPS, XRD, FTIR, and TEM, while spectroscopic characterization revealed interactions between the MOs and PANI. The results showed that the thermal stability was improved when the $\mathrm{MO}$ was incorporated into the polymeric matrix. Moreover, the results revealed that incorporating $\mathrm{TiO}_{2}$ into the PANI matrix improves the optical bandgap of the nanocomposite and decreases electrical conductivity compared to other conducting materials. Furthermore, the electrochemical properties of the hybrid nanocomposites were tested by cyclic voltammetry $(\mathrm{CV})$ and galvanostatic charge/discharge (GCD). The obtained results suggest that the $\mathrm{PANI}_{\mathrm{T}} \mathrm{TiO}_{2}$ nanocomposite could be a promising electrode material candidate for high-performance supercapacitor applications.

Keywords: polyaniline; aluminum oxide; titanium dioxide; titanium carbide; nanocomposites; electrochemical properties

\section{Introduction}

Recently, research on hybrid materials, which mainly focuses on conducting polymers with nanoparticles such as metal oxide (MOs) and $\mathrm{Al}_{2} \mathrm{O}_{3}, \mathrm{TiO}_{2}$, and $\mathrm{TiC}$, has attracted considerable attention due to their wide application in various fields such as sensors, electrodes, batteries, photovoltaics, medicine, electrochemistry, and energy, as well as their ease of fabrication [1]. Additionally, conducting polymers have earned an important role as they are low-cost, are environmentally friendly, and have low toxicity [2,3]. Among them, polyaniline (PANI) is a conducting polymer that has received considerable attention in the industry due to its environmental and thermal stability [4-6]. Moreover, due to its properties such as high conductivity, broad absorbance, simple synthesis, ease of coupling with metal ions, porous morphology structure, and environmental stability, PANI can be used in numerous applications such as supercapacitors, electrochromic devices, sensors, light-emitting diodes (LEDs), and anti-corrosion coatings [7-13].

Due to the large potential of conducting polymers and polymers doped with inorganic nanoparticles, which improve the performance of materials in many applications, 
the fabrication of nanocomposites seems to be a recent challenge. Many authors studied the synthesis of nanocomposites of polyaniline with various nanoparticles such as $\mathrm{Fe}_{3} \mathrm{O}_{4}$ [14], $\mathrm{ZnO}$ [15], $\mathrm{ZrO}_{2}$ [16], $\mathrm{TiO}_{2}$ [17], $\mathrm{Al}_{2} \mathrm{O}_{3}$ [18], $\mathrm{TiC}$ [4], and montmorillonite [19]. With the doping of conductive polymers with metal oxides, defined properties such as high electrical conductivity, high electron affinity, and improved mechanical properties can be achieved [20]. Such conductive polymers doped with nanomaterials are used for different purposes and applications. Naveed-ur-Rehman et al. proposed conducting polymers with metal oxide nanoparticles for the production of electrode materials for supercapacitors. In their study, various nanocomposites containing $\mathrm{Co}_{3} \mathrm{O}_{4}, \mathrm{Pr}_{2} \mathrm{O}_{3}$, and $\mathrm{NiO}$ nanoparticles, binary PANI- $\mathrm{Pr}_{2} \mathrm{O}_{3}, \mathrm{PANI}-\mathrm{NiO}$, and $\mathrm{PANI}-\mathrm{Co}_{3} \mathrm{O}_{4}$ nanoparticles, ternary $\mathrm{Pr}_{2} \mathrm{O}_{3}-\mathrm{NiO}-\mathrm{Co}_{3} \mathrm{O}_{4}$ nanoparticles, and quaternary $\mathrm{PANI}-\mathrm{Pr}_{2} \mathrm{O}_{3}-\mathrm{NiO}-\mathrm{Co}_{3} \mathrm{O}_{4}$ nanoparticles with a spherical core and shell were prepared using coprecipitation and ultrasonic methods [21]. The review by Mohd Abdah et al. explored the use of fibers based on transition metal oxides and conducting polymers for the application area of high-performance supercapacitors [22]. PANI and its composite with $\mathrm{MnO}_{2}$ were successfully deposited by electrochemical methods in the study by Rabbani et al., and the composite electrodes with Fe-PANI and Fe-PANI/ $\mathrm{MnO}_{2}$ showed excellent supercapacitive properties [23]. Lokhanni et al. prepared supercapacitive metal oxide composite electrodes composed of carbon, metal oxides, and conducting polymers [24].

The preparation of nanocomposites with high performance such as high thermal stability and good electrochemical properties has become a major challenge according to the dispersion of nanoparticles in the polymers [25]. To increase the dispersion of nanofillers, the commix method and stearic acid are used to prevent the aggregation of nanoparticles in the polymer matrix [26].

MOs exhibit different electrical behavior that can change from electrically insulating to others such as $\mathrm{Al}_{2} \mathrm{O}_{3}$ and $\mathrm{MgO}$, as well as wide-band semiconductors such as $\mathrm{SnO}_{2}$, $\mathrm{TiO}_{2}, \mathrm{Ti}_{2} \mathrm{O}_{3}$, and $\mathrm{ZnO}$, and metal-like behaviors such as $\mathrm{ReO}_{3}, \mathrm{~V}_{2} \mathrm{O}_{3}$, and $\mathrm{RuO}_{2}$. The metal oxide presents several stable oxidation states, which play a significant role in the surface chemistry of the obtained copolymer [27].

The need for new materials with promising electrochemical performances represents an important target for energy storage applications. In addition, the development of new-generation supercapacitors is associated with numerous problems, such as high selfcharge/discharge currents, low energy density, high equivalent series resistance, and low operating potential. Although MO electrodes are available for supercapacitors, they suffer from poor cycling stability and low current capability [26]. In addition, MOs are relatively expensive compared to carbon materials. Therefore, there is a great need to improve the electrochemical properties of MOs and CPs.

In the present work, three different nanocomposites were prepared from polyaniline and nanoparticles $\left(\mathrm{Al}_{2} \mathrm{O}_{3}, \mathrm{TiC}\right.$, and $\left.\mathrm{TiO}_{2}\right)$ using the in situ polymerization method in the presence of $\mathrm{HCl}$ with ammonium persulfate as an oxidant. The obtained samples were characterized by XRD, XPS, TGA, FTIR, TEM, and CV in order to determine the thermal stability and electrochemical behavior.

\section{Materials and Methods}

\subsection{Materials}

The monomer aniline (ANI) (purity $\geq 99.5 \%$, Sigma-Aldrich, St. Louis, MI, USA), perchloric acid $\left(\mathrm{HClO}_{4}, 70 \%\right.$, Merck KGaA, Darmstadt, Germany), hydrochloric acid $\left(\mathrm{HCl}, 37 \%\right.$, Merck KGaA, Darmstadt, Germany), and ultrapure $\mathrm{H}_{2} \mathrm{O}(18.2 \mathrm{M} \Omega \mathrm{cm}$, ElgaLabwater-Purelab system, ELGA LabWater, Veolia Water Technologies Deutschland GmbH, Celle, Germany) were used in all the experiments. Aluminum oxide nanoparticles $\left(\mathrm{Al}_{2} \mathrm{O}_{3}\right)$ ( $\geq 99.98 \%$, Merck KGaA, Darmstadt, Germany), titanium (IV) oxide $\left(\mathrm{TiO}_{2}\right)(\geq 99.98 \%$, Merck KGaA, Darmstadt, Germany), zinc oxide (ZnO) (99\%, Merck KGaA, Darmstadt, Germany), ammonium persulfate (APS) ( $\geq 98 \%$, Merck KGaA, Darmstadt, Germany), and ammonia 
solution $\left(\mathrm{NH}_{4} \mathrm{OH}\right)(25 \%$, Merck KGaA, Darmstadt, Germany) were used for the preparation of nanocomposites.

\subsection{Chemical Preparation of Hybrid Materials}

PANI and its corresponding nanocomposites, PANI@ $\mathrm{Al}_{2} \mathrm{O}_{3}$, PANI@TiO ${ }_{2}$, and PANI@TiC, were prepared via in situ oxidative polymerization reactions [4,20-22]. A defined amount of $1 \mathrm{~g}$ for each $\mathrm{MOs}\left(\mathrm{Al}_{2} \mathrm{O}_{3}, \mathrm{TiC}\right.$, or $\left.\mathrm{TiO}_{2}\right)$ was dispersed in $1 \mathrm{M} \mathrm{HCl}$ solution under magnetic stirring for $30 \mathrm{~min}$. Then, $135 \mathrm{mg}$ of ANI monomers were added to this mixture dropwise and stirred for $30 \mathrm{~min}$ to inhibit nanoparticle agglomeration and allow for the electrostatic interactions to deposit HCl-doped aniline on the surface of MOs. Afterward, the polymerization was initiated by the APS added dropwise in a stoichiometric ratio to the monomer (applied 1:1 oxidant/monomers molar ratio). The mixture was stirred for $24 \mathrm{~h}$ at room temperature. The next day, the precipitate was collected on a filter paper, washed with distilled $\mathrm{H}_{2} \mathrm{O}$ and acetone, and finally placed in $50 \mathrm{~mL}$ of $\mathrm{NH}_{4} \mathrm{OH}(1 \mathrm{M})$ at $25^{\circ} \mathrm{C}$ and stirred for $2 \mathrm{~h}$. The final products were filtered, washed with deionized water, and dried under vacuum at $65^{\circ} \mathrm{C}$ for $24 \mathrm{~h}[4,27-29]$.

\subsection{Physicochemical Characterization}

X-ray photoelectron spectroscopy (XPS) was performed to measure the surface components of materials using an AVG-Microtech-Multilab 3000-electron spectrometer (VG Microtech Ltd., London, UK). A Hitachi U-3000 spectrophotometer (Hitachi High-Technologies Corporation, Tokio, Japan) was used to measure UV/Vis spectra. The X-ray diffraction of the samples was acquired by applying a Bruker CCD-Apex (Madison, WI, USA) equipment. For transmission electron microscopy (TEM) observations, the materials were dispersed in ethanol and supported on TEM grids. The images were collected using a JEOL-JEM2010 microscope (Jeol, Peabody, MA, USA). Thermogravimetric analysis (TGA) (Hitachi STA7200 instrument, Fukuoka, Japan) was performed with a DuPont thermogravimetric analyzer at a heating rate of $20 \mathrm{~K} \cdot \mathrm{min}^{-1}$ under $\mathrm{N}_{2}$. About $10 \mathrm{mg}$ of material was heated up to $900{ }^{\circ} \mathrm{C}$. Fourier-transform infrared (FTIR) spectroscopy (Varian, Inc., Palo Alto, CA, USA) was performed using the Bruker-Alpha equipment [28,29].

Electrical conductivity measurements were performed using a Lucas Lab resistivity equipment with four in-line probes. The materials were dried for $24 \mathrm{~h}$, and then pellets with a diameter of $0.013 \mathrm{~cm}$ were prepared using an FTIR mold by applying a pressure of $7.4 \times 10^{8} \mathrm{~Pa}$.

\subsection{Electrochemical Properties}

The electrochemical behavior of the materials was characterized by cyclic voltammetry (CV). The materials were first dissolved in NMP [4]. Then, a drop of the resulting solution was placed on the graphite carbon electrode and dried in air under an infrared lamp to solvent remove. The electrochemical studies were performed using a conventional three-electrode cell. The reference and counter electrodes were a Pt wire and a reversible hydrogen electrode (RHE) submerged in the electrolyte, respectively. $\mathrm{HClO}_{4}(1 \mathrm{M})$ was used as an electrolyte in all experiments.

\section{Results and Discussions}

\subsection{X-ray Photoelectron Spectroscopy (XPS) Spectra}

The surface characteristics of PANI@ $\mathrm{Al}_{2} \mathrm{O}_{3}$, PANI@TiO were investigated by XPS analyses. The XPS spectra of all hybrid materials showed the existence of contributions from N 1s, confirming the presence of the PANI chain in these samples (Figure 1). Furthermore, the results show that the addition of the MOs used as support in the polymer matrix led to the detection of new peaks. Therefore, $\mathrm{PANI} @ \mathrm{TiO}_{2}$ and PANI@TiC nanocomposites showed peaks at $459 \mathrm{eV}$ and $462 \mathrm{eV}$, which correspond to Ti $2 p_{3 / 2}$ and Ti $2 p_{1 / 2}$, respectively. In addition, two new peaks near $74 \mathrm{eV}$ and $117 \mathrm{eV}$ 
were visible in the XPS spectrum of $\mathrm{PANI} @ \mathrm{Al}_{2} \mathrm{O}_{3}$, which were assigned to $\mathrm{Al} 2 p$ and $\mathrm{Al} 2 s$ species, respectively.

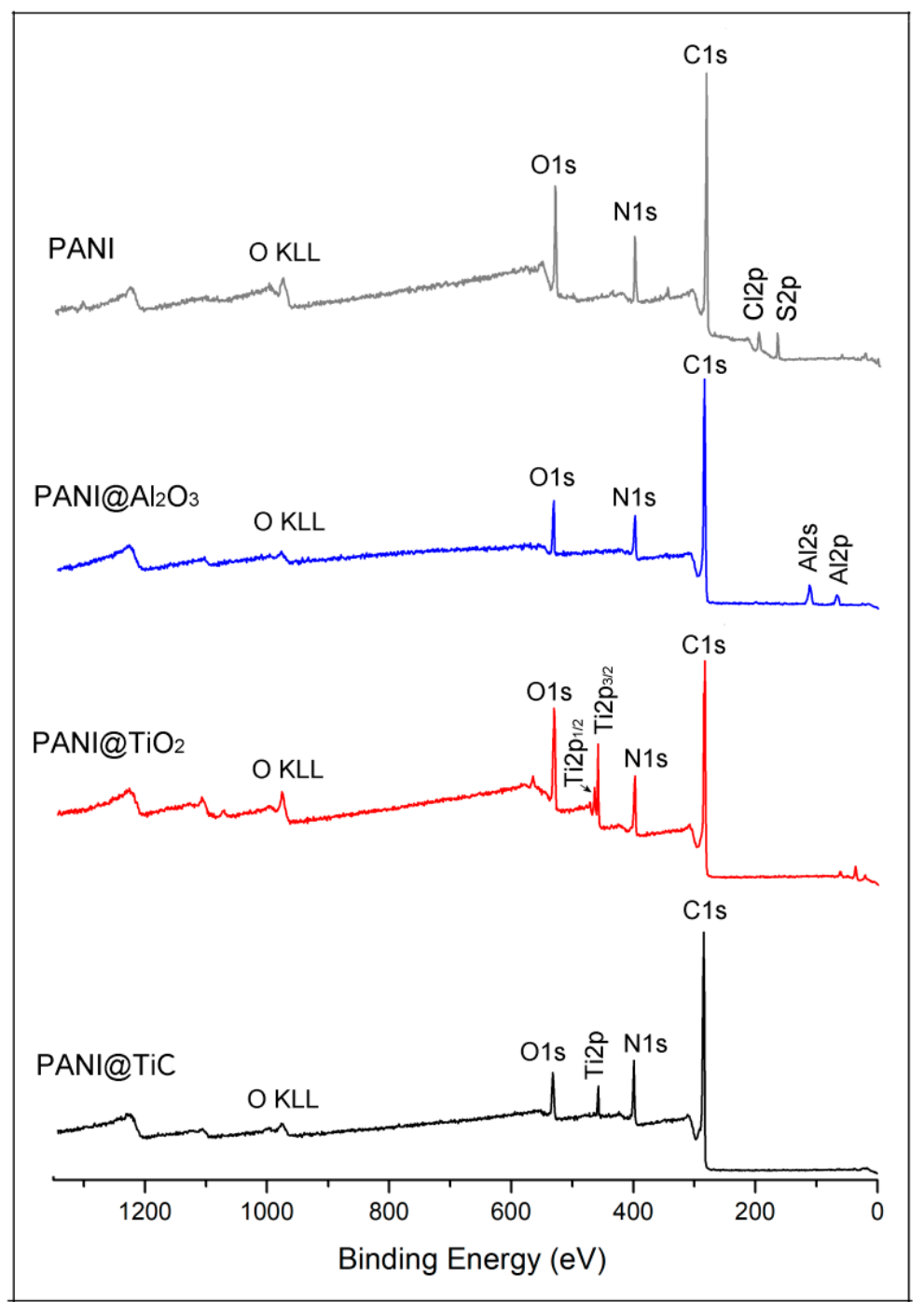

Figure 1. X-ray photoelectron spectroscopy (XPS) survey scan spectrum of synthesized materials.

To further investigate the change in the electronic structure of the hybrid materials, Gaussian deconvolution peak integration was used to calculate the respective proportions of the $\mathrm{N} 1$ s peak (Figure 2). In this way, the $\mathrm{N} 1$ s spectrum of the $\mathrm{PANI}_{\mathrm{TiO}}$ sample can be subdivided into three peaks, for which the assignment of the binding energies is listed in Table 1. The first peak at $398.39 \mathrm{eV}$ corresponded to neutral amines, the second peak at $399.53 \mathrm{eV}$ corresponded to imine species, and the last peak at $400.33 \mathrm{eV}$ could be assigned to the nitrogen cationic radical $\left(-\mathrm{N}^{+}\right)$, which is also present in the structure of PANI [30]. Similarly, for the PANI@TiC sample, the three peaks appearing at $398.51 \mathrm{eV}, 399.71 \mathrm{eV}$, and $400.83 \mathrm{eV}$ corresponded to quinoid amine $(-\mathrm{N}=)$ and benzenoid amine $\left(-\mathrm{NH}-\right.$ and $\left.-\mathrm{N}^{+}\right)$. In contrast, the spectrum of PANI@ $\mathrm{Al}_{2} \mathrm{O}_{3}$ showed only two peaks at $398.22 \mathrm{eV}$ and $399.48 \mathrm{eV}$, which could be assigned to $-\mathrm{N}=$ and $-\mathrm{NH}-$, respectively. 


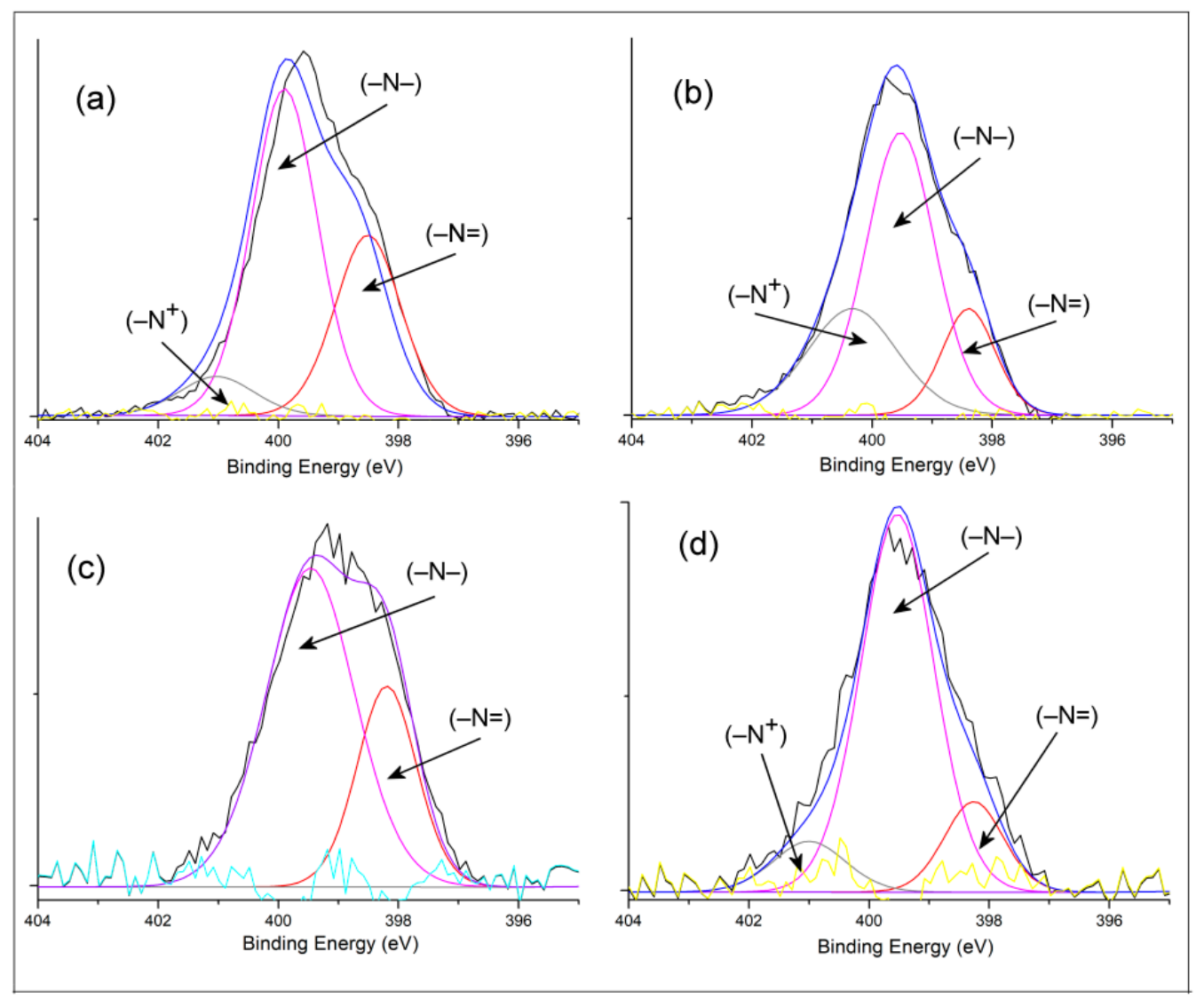

Figure 2. XPS spectra in N 1s region of (a) PANI@TiC, (b) PANI@ $\mathrm{TiO}_{2}$, (c) PANI@ $\mathrm{Al}_{2} \mathrm{O}_{3}$, and (d) PANI samples.

Table 1. N 1s data, intrinsic oxidation state, and doping degree of conducting materials from XPS results.

\begin{tabular}{|c|c|c|c|c|c|}
\hline \multirow{2}{*}{ Materials } & \multicolumn{5}{|c|}{ Binding Energy (eV) } \\
\hline & & N1s & & {$[=\mathrm{N}-] /[\mathrm{N}-\mathrm{H}]$} & {$\left[\mathbf{N}^{+}\right] /[=\mathbf{N}-+\mathbf{N}-\mathbf{H}]$} \\
\hline PANI@TiC & 398.51 & 399.71 & 400.83 & 0.56 & 0.05 \\
\hline PANI@ $\mathrm{TiO}_{2}$ & 398.39 & 399.53 & 400.33 & 0.29 & 0.51 \\
\hline PANI@ $\mathrm{Al}_{2} \mathrm{O}_{3}$ & 398.22 & 399.48 & // & 0.42 & // \\
\hline PANI & 398.24 & 399.52 & 400.99 & 0.22 & 0.60 \\
\hline Assignments & $=\mathrm{N}-$ & $-\mathrm{NH}-/-\mathrm{NC}-$ & $-\mathrm{N}^{+}-/=\mathrm{N}^{+}-$ & & \\
\hline
\end{tabular}

On the other hand, the ratio of the areas under $[=\mathrm{N}-] /[-\mathrm{NH}-]$ compositions indicates the quantitative intrinsic oxidation state (OS) of the samples [23]. The area ratio of the lowest binding energy to the total area band is an indicator of the doping degree (DD) [30]. The quantitative data on the intrinsic oxidation state and doping level of the hybrid materials are listed in Table 1 . The OS of PANI@TiC was 0.56 , and the defect density was only 0.05 , while the OS of PANI@TiO ${ }_{2}$ was 0.29 , and the defect density was up to 0.51 . This latter nanocomposite had a weak OS and higher DD, which probably resulted in a faster charging/discharging ratio and significant capacitance. These different data of the $\mathrm{N} 1 \mathrm{~s}$ spectra indicate that these conducting materials had different distributions, i.e., different doping states.

\subsection{Fourier-Transform Infrared Spectroscopy (FTIR) Spectra}

Figure 3 shows the FTIR spectra of PANI and its nanocomposites. The characteristic peaks of PANI at 3088-3258 $\mathrm{cm}^{-1}$ were attributable to the stretching of $\mathrm{N}-\mathrm{H}$ [31-33], and the peaks at $1643-1546 \mathrm{~cm}^{-1}$ and $1472-1506 \mathrm{~cm}^{-1}$ were due to the $C=N$ and $C=C$ stretching modes for the quinoid and benzenoid rings [32-34], respectively. The bands at about 
$1304 \mathrm{~cm}^{-1}$ and $1243 \mathrm{~cm}^{-1}$ corresponded to the stretching of $\mathrm{C}-\mathrm{N}$ bonds in the benzenoid ring, whereas the bands between 1000 and $1129 \mathrm{~cm}^{-1}$ were assigned to a planar vibrational flexion of $\mathrm{C}-\mathrm{H}$ bonds [32-34]. The band at $803 \mathrm{~cm}^{-1}$ represented the stretching of $\mathrm{C}-\mathrm{H}$ out-of-plane bending vibration [31].

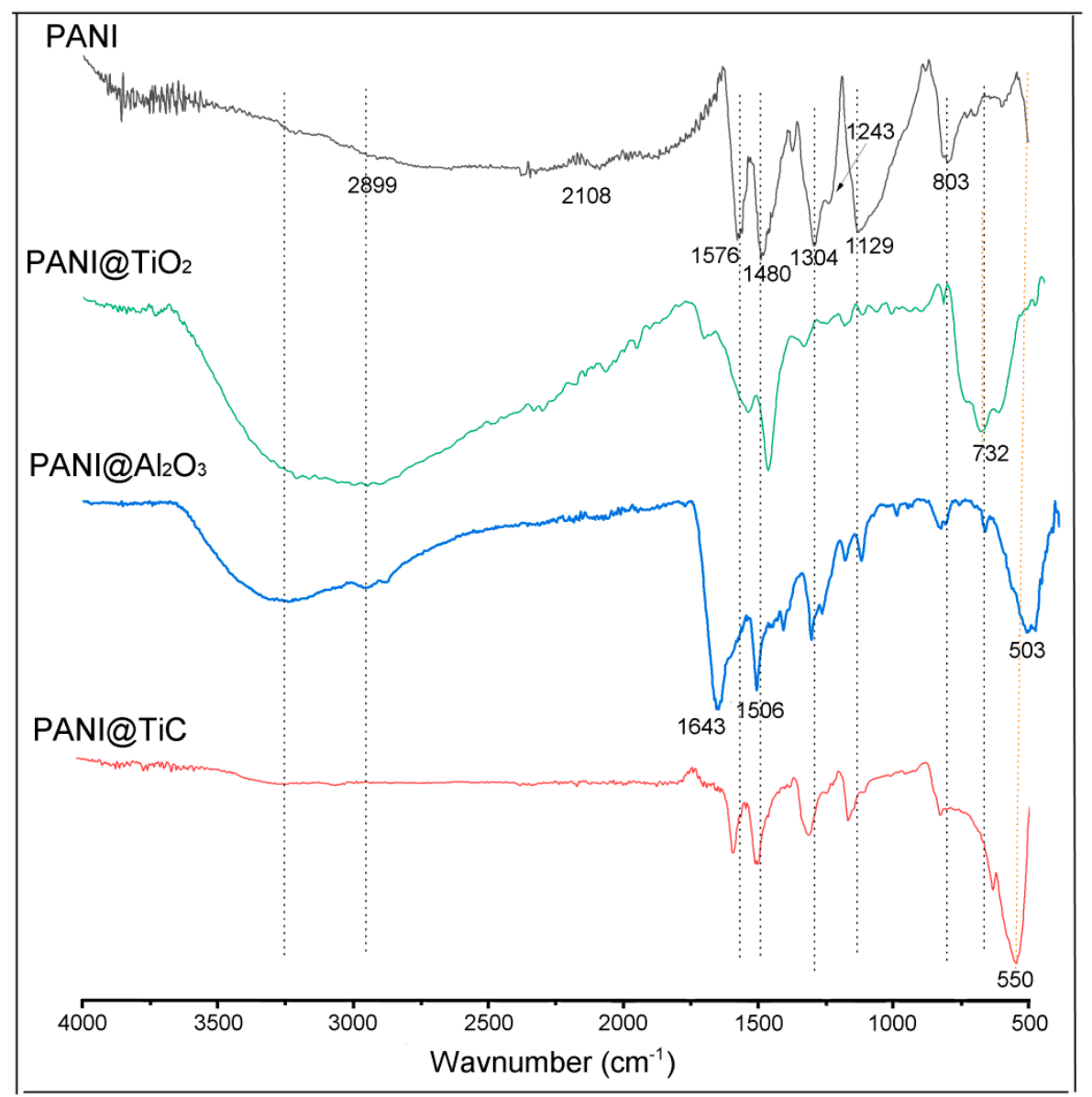

Figure 3. Fourier-transform infrared spectroscopy (FTIR) spectra of synthesized materials.

The FTIR spectra of nanocomposites show that these materials contained the same characteristic PANI bands, while some bands presented a shifting compared to PANI, which may be associated with the interaction existing between $\mathrm{MO}$ and polymer.

The spectrum of the PANI@ $@ \mathrm{TiO}_{2}$ nanocomposite showed a characteristic band at $732 \mathrm{~cm}^{-1}$, which was attributed to the Ti-O stretching band [35]. The presence of TiC bands at $635 \mathrm{~cm}^{-1}$ and $550 \mathrm{~cm}^{-1}$ in the IR spectrum of PANI@TiC nanocomposite confirmed the incorporation of TiC into the PANI matrix [4]. For the PANI@ $\mathrm{Al}_{2} \mathrm{O}_{3}$ nanocomposite, the band at $503 \mathrm{~cm}^{-1}$ was seen to be attributed to condensed octahedral $\mathrm{AlO}_{6}$ [18]. The shift of the peak positions observed confirmed the interaction between PANI and $\mathrm{Al}_{2} \mathrm{O}_{3}$.

\subsection{X-ray Diffraction (XRD) Studies}

Figure 4 exhibits a comparison of the XRD patterns of $\mathrm{PANI}, \mathrm{TiO}_{2}, \mathrm{PANI} / \mathrm{TiO}_{2}, \mathrm{TiC}$, PANI@TiC, $\mathrm{Al}_{2} \mathrm{O}_{3}$, and PANI@ $\mathrm{Al}_{2} \mathrm{O}_{3}$. The XRD pattern of PANI displayed two peaks at $2 \theta=20^{\circ}$ and $25^{\circ}$, which were attributed to the (100) and (110) planes, respectively [31,35]. These peaks can be attributed to the parallel and perpendicular periodicity of the PANI chain and are characteristic of the protonated form of PANI [35,36]. For nanocomposites, all peaks were present for the $\mathrm{MOs}$ of $\mathrm{TiC}, \mathrm{Al}_{2} \mathrm{O}_{3}$, and $\mathrm{TiO}_{2}$, while the broad peaks between $10^{\circ}$ and $30^{\circ}$ attributed to the amorphous structures of PANI confirmed the polymer-MO interaction [18]. The characteristic diffraction patterns of the titania anatase phase $\left(\mathrm{TiO}_{2}\right)$ were observed at $2 \theta=25.28^{\circ}, 36.9^{\circ}, 37.81^{\circ}, 38.57^{\circ}, 48.05^{\circ}, 53.85^{\circ}, 55.03^{\circ}, 62.12^{\circ}, 62.69^{\circ}$, and 
$68.76^{\circ}$ which were associated with the (101), (103), (004), (112), (200), (105), (211), (213), (204), and (116) crystal planes, respectively [37]. A peak around $32^{\circ}$ was found in the PANI@ $\mathrm{TiO}_{2}$ nanocomposites, which could be attributed to the polymers, and there was a small peak at an angular position of $2 \theta=23^{\circ}$, which represented the emeraldine salt form of PANI.

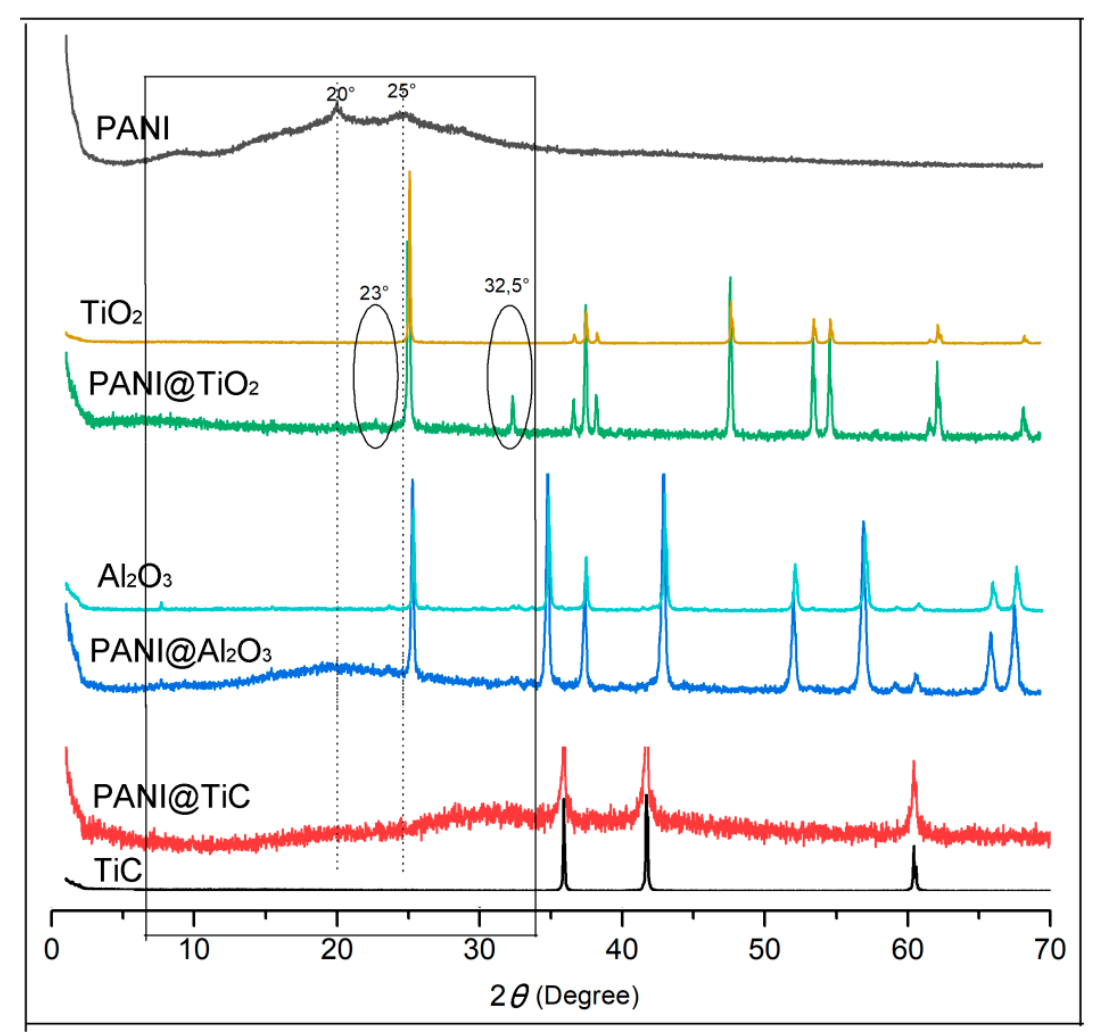

Figure 4. X-ray diffraction (XRD) patterns of the PANI, PANI@ $\mathrm{TiO}_{2}, \mathrm{PANI} @ \mathrm{TiC}, \mathrm{PANI} @ \mathrm{Al}_{2} \mathrm{O}_{3}, \mathrm{TiO}_{2}$, $\mathrm{TiC}$, and $\mathrm{Al}_{2} \mathrm{O}_{3}$ materials.

\subsection{UV/Visible (UV/Vis) Spectroscopy}

Figure 5a presents the UV/Vis absorption spectra of PANI, PANI@TiC, PANI@TiO ${ }_{2}$, and PANI@ $\mathrm{Al}_{2} \mathrm{O}_{3}$, where these samples were dissolved in NMP. The materials displayed two characteristic absorption bands. The first band at 314-394 $\mathrm{nm}$ could be attributed to the $\pi-\pi^{*}$ transition of the benzenoid ring; the second band between 591 and $616 \mathrm{~nm}$ could be ascribed to the transition of the exciton of the quinone, indicating the delocalization of electrons in the polymer [38] (the various transitions are included in Table 2).

Table 2. Absorption band, redox peak, and bandgap energy $\left(E_{g}\right)$ of the synthesized materials.

\begin{tabular}{|c|c|c|c|c|c|c|c|c|c|}
\hline \multirow{2}{*}{ Materials } & \multicolumn{2}{|c|}{ Absorption Band (nm) } & \multicolumn{6}{|c|}{ Redox Peaks (V) } & \multirow{2}{*}{$E_{g}(\mathrm{eV})$} \\
\hline & $\pi-\pi^{*}$ & $\mathbf{n}-\pi^{*}$ & $E_{o x 1}$ & $E_{\text {red1 }}$ & $\Delta E_{p 1}$ & $E_{o x 2}$ & $E_{\text {red } 2}$ & $\Delta E_{p 2}$ & \\
\hline PANI & 314 & 591 & 0.40 & 0.28 & 0.12 & 0.93 & 0.84 & 0.09 & 3.22 \\
\hline PANI@ $\mathrm{Al}_{2} \mathrm{O}_{3}$ & 380 & 606 & 0.48 & 0.32 & 0.16 & 0.86 & 0.74 & 0.12 & 2.64 \\
\hline PANI@TiC & 394 & 603 & 0.44 & 0.25 & 0.19 & 0.75 & 0.59 & 0.25 & 3.20 \\
\hline PANI@TiO 2 & 316 & 616 & 0.38 & 0.24 & 0.06 & 0.69 & 0.56 & 0.13 & 2.62 \\
\hline
\end{tabular}




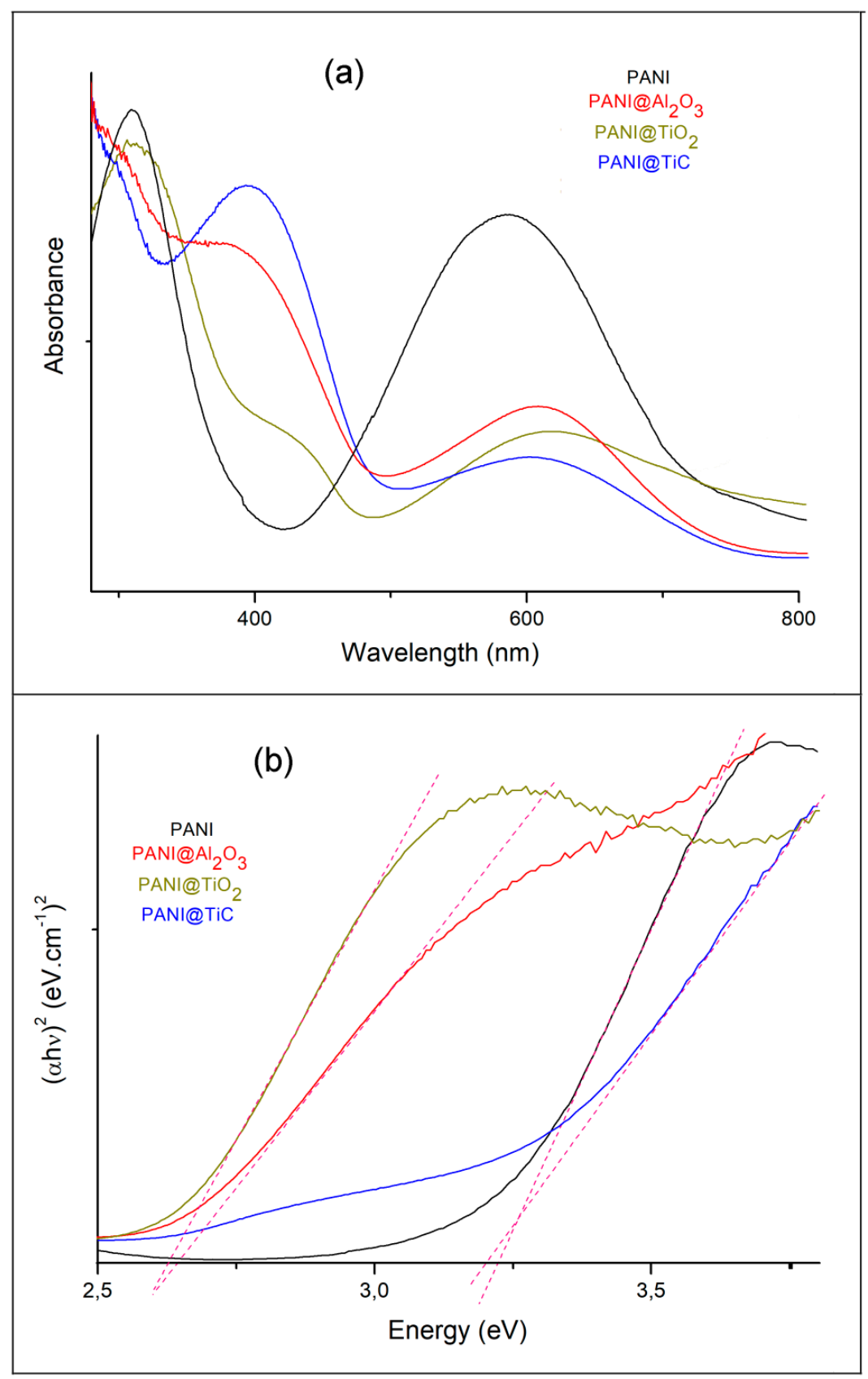

Figure 5. UV/visible (UV/Vis) spectroscopy absorption spectra (a) and Tauc plots (b) of synthesized samples.

In the nanocomposites, the intensity of the $\pi-\pi^{*}$ and $n-\pi^{*}$ transitions of the bands decreased compared to PANI, and these bands were shifted to lower wavelengths [11]. They affected the electron distribution in the benzene ring region and formed a large conjugated system, which was due to the incorporation of MOs into the PANI matrix [33]. This confirmed that the presence of nanoparticles had an impact on the level of PANI doping, which was evident in the crystalline form [33].

It can be observed that the PANI@ $\mathrm{TiO}_{2}$ exhibited the lowest intensity, indicating that the doping level of the $\mathrm{TiO}_{2}$-based nanocomposite was lower than that of $\mathrm{TiC}$ - and $\mathrm{Al}_{2} \mathrm{O}_{3}$-based samples.

The results of the UV/Vis investigation showed an electronic interaction between $\mathrm{MO}$ and PANI, which was attributed to a coordination bond between the pair of lone electrons of amine nitrogen and the empty orbitals of $\mathrm{MO}$ [39]. 
The UV/Vis spectra provide insight into the optical properties and bandgap energy values. The indirect bandgap energies of materials can be obtained from the Tauc plot (Figure $5 \mathrm{~b}$ ) of $\left(A^{2}\right)$ versus photon energy $(h v)$ as follows [30]:

$$
A=\left(h v-E_{g}\right)^{1 / 2},
$$

where $h$ is Planck's constant, $h v$ is photon energy, $A$ is the absorption coefficient for direct transitions, $n=\frac{1}{2}$, and $E_{g}$ is the optical energy gap.

The bandgap values obtained were $3.22 \mathrm{eV}, 3.20 \mathrm{eV}, 2.64 \mathrm{eV}$, and $2.62 \mathrm{eV}$ for PANI, PANI@TiC, PANI@ $\mathrm{Al}_{2} \mathrm{O}_{3}$, and PANI@TiO ${ }_{2}$, respectively (Table 2). Furthermore, the bandgap energy value of the $\mathrm{PANI}_{\mathrm{N}} \mathrm{TiO}_{2}$ sample was lower compared to the other cases due to the strong interaction between $\mathrm{PANI}$ and $\mathrm{TiO}_{2}$, which caused changes in the electron density of the PANI chain. These changes caused a red shift, i.e., the absorption shifted to a longer wavelength [40]. On the other hand, this observed trend could be explained by the different crystallite structures. In addition to the impact of the crystal phase, the size of the MOs is considered to play a dominant role in their optical properties.

\subsection{Thermogravimetric Analysis (TGA)}

Using TGA, the thermal stability of the synthesized materials was investigated by monitoring the reduction in mass as a function of temperature. The TGA profiles of all samples are shown in Figure 6. The curves of each hybrid material exhibited a common feature, i.e., thermal decomposition in three different ranges. An initial weight loss ( $\sim 5 \%)$ at a temperature $>120^{\circ} \mathrm{C}$ was associated with the evaporation of entrapped water, solvent, or monomer molecules in the sample [41]. This was followed by a second weight loss in the range of 150 to $450^{\circ} \mathrm{C}$ due to the PANI chain doping and polymer moiety degradation [18]. In the third stage, which occurred at a temperature of $>550{ }^{\circ} \mathrm{C}$, the thermal stability was different; the weight loss varied between $15 \%$ and $30 \%$ for hybrid materials, whereas it was $57 \%$ for PANI. These results indicate that the nanocomposite of PANI@ $\mathrm{Al}_{2} \mathrm{O}_{3}$ exhibited higher resistance to thermal degradation, as it had a total mass loss of $15 \%$ at $700{ }^{\circ} \mathrm{C}$. In contrast, the PANI@TiC and PANI@ $\mathrm{TiO}_{2}$ nanocomposites exhibited a higher mass loss of $28 \%$ and $30 \%$, respectively. Moreover, the TGA curve of PANI@ $\mathrm{Al}_{2} \mathrm{O}_{3}$ displayed a lower weight loss compared to the other two nanocomposites, indicating an improved thermal stability. This pronounced enhancement in thermal stability was mainly due to the strong $\pi$-stacking interaction between the benzene rings from PANI (aniline molecules) and the $\mathrm{Al}_{2} \mathrm{O}_{3}$ nanoparticle surface [42]. Due to the large surface area of the nanostructured $\mathrm{Al}_{2} \mathrm{O}_{3}$, the contact area between PANI and $\mathrm{Al}_{2} \mathrm{O}_{3}$ was sufficiently large to enhance the stability. It has previously been demonstrated that nanoparticles of $\mathrm{TiC}, \mathrm{Al}_{2} \mathrm{O}_{3}$, and $\mathrm{TiO}_{2}$ exhibit strong thermal stability in the studied temperature range $[4,18,28,43]$.

\subsection{Transmission Electron Microscopy (TEM) Analysis}

Figure 7 shows the TEM images of $\mathrm{Al}_{2} \mathrm{O}_{3}, \mathrm{TiC}$, and $\mathrm{TiO}_{2}$ nanoparticles and $\mathrm{PANI} \mathrm{Al}_{2} \mathrm{O}_{3}$, PANI@TiC, and PANI@TiO ${ }_{2}$ nanocomposites. The $\mathrm{MO}$ nanoparticles in Figure 7A,C depict a spherical morphology, except for the $\mathrm{TiC}$ nanoparticles Figure 7B, which had a cuboidal shape. The average size of the $\mathrm{Al}_{2} \mathrm{O}_{3}$ and $\mathrm{TiO}_{2}$ nanoparticles was $37 \mathrm{~nm}$ and $28 \mathrm{~nm}$, respectively. Moreover, the PANI@ $\mathrm{Al}_{2} \mathrm{O}_{3}$ nanocomposite surface (Figure 7D) became more distinct compared to the pure nanoparticles (Figure 7A), which could be attributed to polymerization at the $\mathrm{Al}_{2} \mathrm{O}_{3}$ surface and a strong interfacial interaction between the nanoparticles and the PANI matrix [42]. However, the TEM image of TiC nanoparticles displayed a black streak [43]. Moreover, TEM images of the nanocomposites show that all MOs were well dispersed in the PANI matrix [44]. In addition, the morphology of all hybrid materials was found to be spherical with a size of $34-82 \mathrm{~nm}$. 


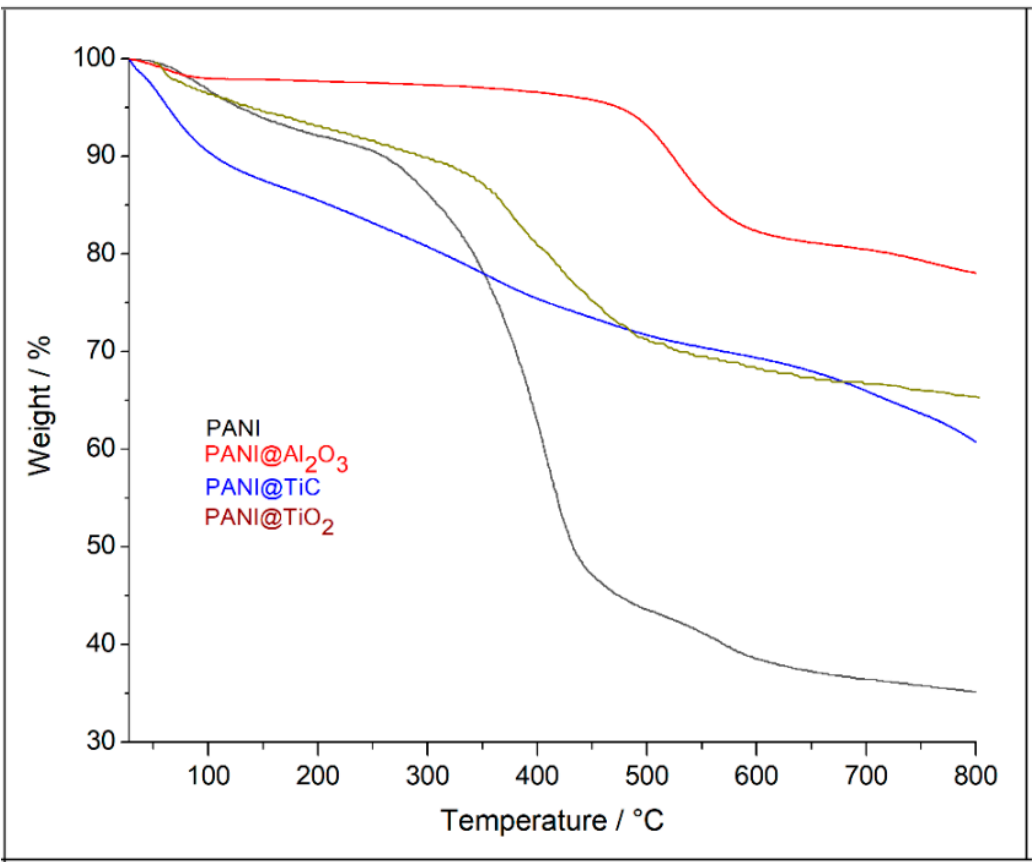

Figure 6. Thermogravimetric analysis (TGA) curves of PANI, PANI@ $\mathrm{Al}_{2} \mathrm{O}_{3}, \mathrm{PANI@TiO}$, and PANI@TiC.

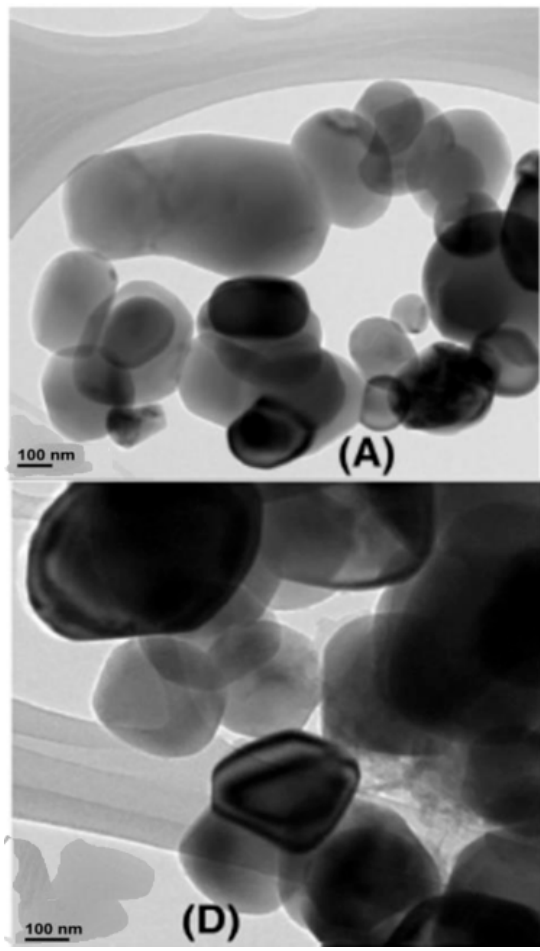

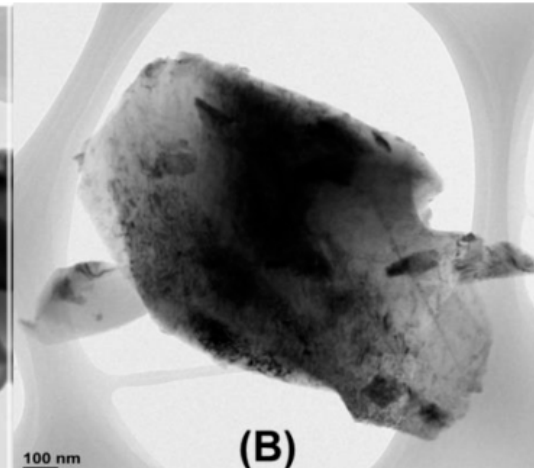
$100 \mathrm{~nm}$

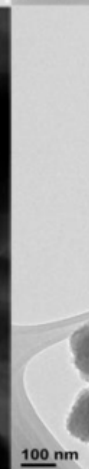

(B)

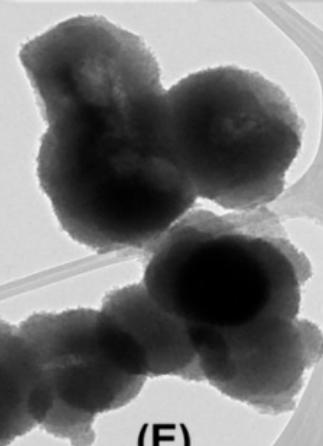

(E)

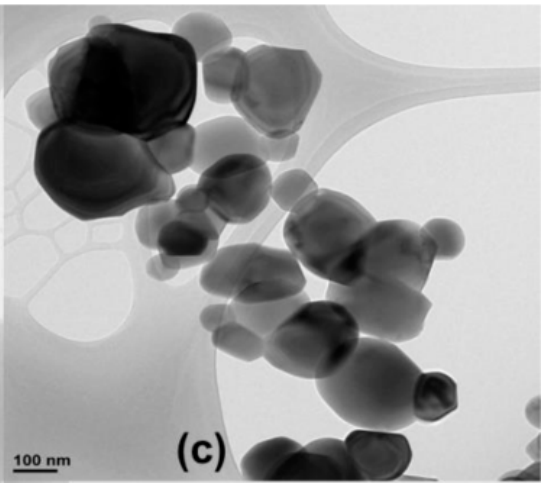

$100 \mathrm{~nm}$

(c)

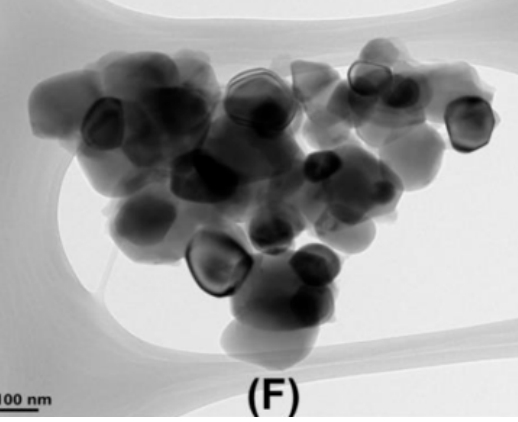

Figure 7. Transmission electron microscopy (TEM) images of (A) $\mathrm{Al}_{2} \mathrm{O}_{3},(\mathbf{B}) \mathrm{TiC},(\mathbf{C}) \mathrm{TiO}_{2},(\mathbf{D}) \mathrm{PANI}_{\mathrm{Al}} \mathrm{Al}_{3},($ E) $\mathrm{PANI} \mathrm{TiC}$, and (F) PANI@TiO .

\subsection{Electrochemical Properties}

Cyclic voltammetry (CV) was performed to examine the polymer electroactivity. Figure 8a displays the CVs for PANI, PANI@TiC, PANI@ $\mathrm{Al}_{2} \mathrm{O}_{3}$, and PANI@TiO 2 materials obtained in $\mathrm{HClO}_{4}$ solution $(1 \mathrm{M})$ at a scan rate of $50 \mathrm{mV} \cdot \mathrm{s}^{-1}$. 

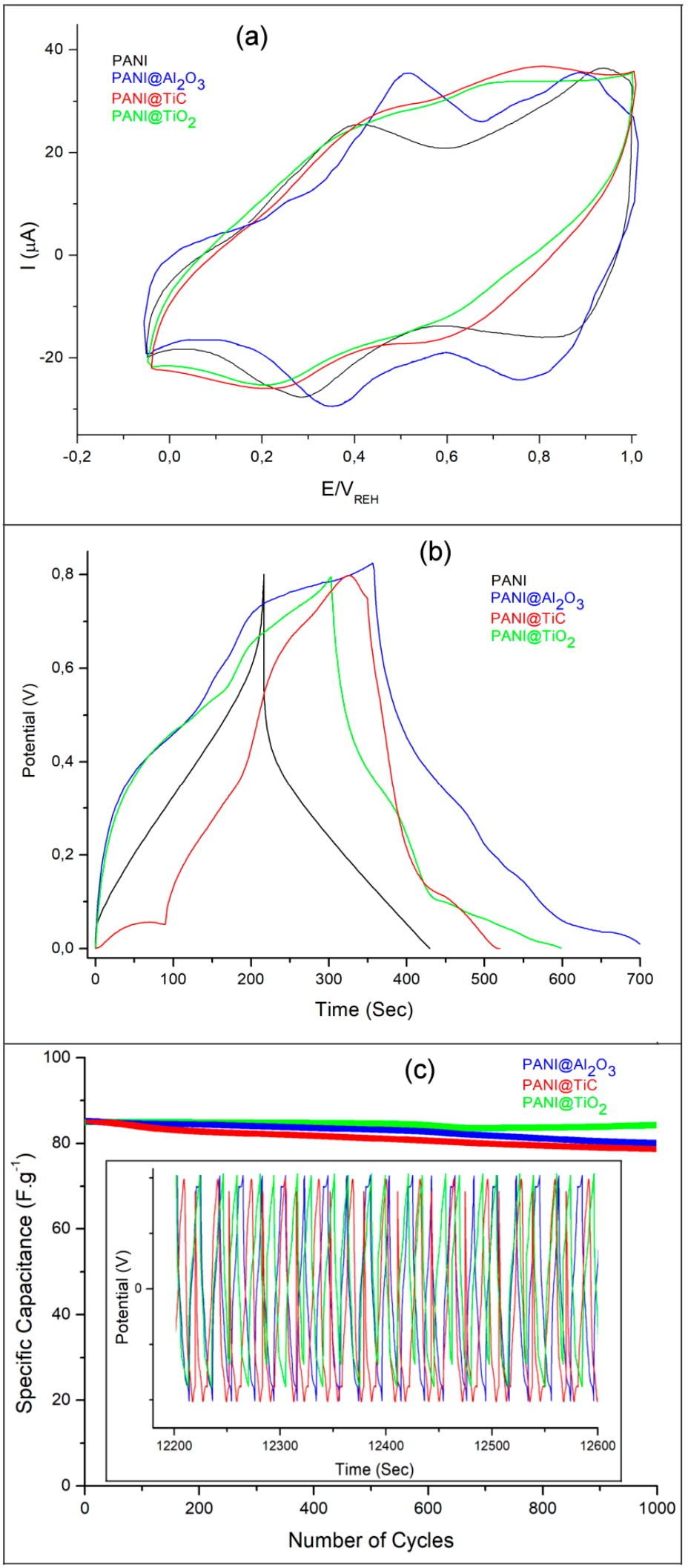

Figure 8. (a) Cyclic voltammograms recorded for a graphite carbon electrode covered by samples in $\mathrm{HClO}_{4}$ solution $(1 \mathrm{M})$ at a scan rate of $50 \mathrm{mV} \cdot \mathrm{s}^{-1},(\mathbf{b})$ galvanostatic charge-discharge curves at various current densities, and (c) cyclic stability at $1.0 \mathrm{~A} \cdot \mathrm{g}^{-1}$ over 1000 cycles for materials. 
All samples exhibited a nearly rectangular shape with two sets of distinct redox activities, as indicated by the two pairs of anodic and cathodic current peaks [44]. This shape is characteristic for supercapacitors and the typical Faradaic energy storage mechanism of PANI, which has been reported several times in the literature [8]. Furthermore, the anodic and cathodic peaks of PANI@ $\mathrm{Al}_{2} \mathrm{O}_{3}$ were observed to be symmetrical, reflecting superior reversibility of the relevant redox reactions, and that most of the energy is stored by Faradic reactions [45], with the first peaks occurring at $0.48 \mathrm{~V} / 0.32 \mathrm{~V}$ (Table 2), resulting in a potential peak separation $\left(\Delta E_{p}\right)$ close to $160 \mathrm{mV}$. These peaks corresponded to the oxidation of the leucoemeraldine-emeraldine form. Another pair of peaks at $0.86 \mathrm{~V} / 0.74 \mathrm{~V}$ presented a $\Delta E_{p}$ value of $120 \mathrm{mV}$ corresponding to the oxidation of the emeraldine to pernigraniline of polyaniline $[38,40]$. The presence of $\mathrm{TiO}_{2}$ nanoparticles in $\mathrm{PANI} @ \mathrm{TiO}_{2}$ resulted in a shift of ox/red peaks to a lower potential. This indicates that the reaction kinetics were surface-limited, and that the electrochemical properties were determined not only by the nature of the polymer matrix, but also by the MOs [46].

Figure $8 \mathrm{~b}$ shows the galvanostatic charge/discharge (GCD) curves of all the materials, which were carried out at a current density of $1.0 \mathrm{~A} \cdot \mathrm{g}^{-1}$ in the potential range from 0.2 to $0.8 \mathrm{~V}$. The charging slopes of $\mathrm{PANI} @ \mathrm{TiO}_{2}$ showed a fast voltage rise from $0 \mathrm{~V}$ to $0.3 \mathrm{~V}$, which was also due to the equivalent series resistance (ESR), followed by a flattening of the curve at about $0.4 \mathrm{~V}$ to $0.5 \mathrm{~V}$, due to the oxidation of emeraldine to pernigraniline, the major redox transition where energy is stored [7]. In contrast, $\mathrm{PANI} @ \mathrm{Al}_{2} \mathrm{O}_{3}$ exhibited a distorted triangular shape with a shoulder at $0.78 \mathrm{~V}$. This distortion was caused by the pseudocapacitive behavior due to the fast reaction of the PANI redox processes. However, the charging and discharging time constants were much larger for the other samples, indicating an important contribution of the $\mathrm{Al}_{2} \mathrm{O}_{3}$ nanoparticles to the charge storage process. In addition, the PANI@TiC curve exhibited an almost equilateral triangle shape, also indicating the good efficiency of the GCD process. There is a linear relationship between potential and time during GCD processes, which is another reason for the capacitance behavior of a material in addition to exhibiting rectangular CVs. Therefore, it is clear that the presence of crystalline MO nanoparticles with high porosity could enhance the stability of the materials. This result confirmed that the nanocomposites had a high electrochemical reversibility.

Cycling stability is a key factor in the operation of supercapacitors. Conductive polymers in supercapacitors often have limited cycling stability due to shrinkage and swelling during charging/discharging operation [7,47]. In this work, the cycling performance of the hybrid materials exhibited excellent stability with capacity retention between $78.4 \%$ and $84.8 \%$ after 1000 cycles at a high current density of $1.0 \mathrm{~A} \cdot \mathrm{g}^{-1}$ (Figure $8 \mathrm{c}$ ), whereas PANI@TiO ${ }_{2}$ showed superior cycling stability $(84.8 \%)$ without significant loss of specific capacitance compared to the other samples.

\subsection{Conductivity Measurement}

Conductivity measurements were carried out by a four-point probe method. The conductivity of the hybrid materials was low compared to that of pure PANI. The main reason seemed to be stereochemical differences between these nanocomposites. The oxidized PANI had an almost planar structure with a low ionization potential due to strong delocal-

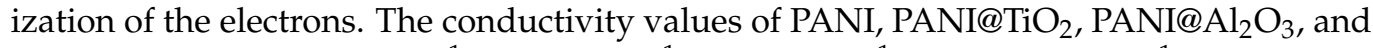
PANI@TiC were $1.457 \mathrm{~S} \cdot \mathrm{cm}^{-1}, 1.029 \mathrm{~S} \cdot \mathrm{cm}^{-1}, 0.921 \mathrm{~S} \cdot \mathrm{cm}^{-1}$, and $0.682 \mathrm{~S} \cdot \mathrm{cm}^{-1}$, respectively. Moreover, the $\mathrm{CV}$ and $\mathrm{GCD}$ were used to test the electrochemical behavior of the hybrid

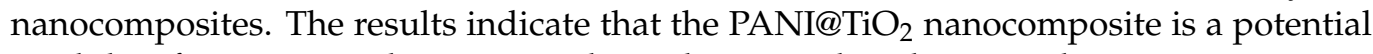
candidate for use as an electroactive electrode material in electronic devices.

\section{Conclusions}

Three PANI@MO hybrid materials were synthesized via in situ polymerization using ammonium persulfate as an oxidant. For this purpose, a comparative study of three metal oxides (MOs) $\left(\mathrm{TiO}_{2}, \mathrm{TiC}\right.$, and $\left.\mathrm{Al}_{2} \mathrm{O}_{3}\right)$ was carried out. The as X-ray photoelectron spectroscopy (XPS), X-ray diffraction (XRD), and Fourier-transform infrared spectroscopy 
(FTIR) analyses confirmed the successful preparation of the PANI@MO nanocomposites. Furthermore, the transmission electron microscopy (TEM) images displayed the spherical morphology of nanocomposites with a size of $34-82 \mathrm{~nm}$. In addition, the optical properties of the samples were investigated. The optical bandgap energies reached about $3.22 \mathrm{eV}$, 3.20 eV, 2.64 eV, and 2.62 eV for PANI, PANI@TiC, PANI@ $\mathrm{Al}_{2} \mathrm{O}_{3}$, and PANI@ $\mathrm{TiO}_{2}$ samples, respectively. The electrical conductivity of the organic@inorganic samples was lower than that of pure PANI. Moreover, the thermogravimetric analysis (TGA) results showed that the decomposition of the nanocomposites was lower than that of the pure polyaniline, confirming the successful synthesis of the products. Furthermore, the electrochemical properties of the materials were tested by cyclic voltammetry, galvanostatic charge/discharge, and cycling stability techniques. The findings of this work may significantly advance the future of supercapacitor electrodes made from nanocomposite materials.

Author Contributions: Conceptualization, A.B. (Amina Bekhoukh), I.M., and L.S.; visualization, A.B. (Amina Bekhoukh), I.M., L.S., and A.B. (Abdelghani Benyoucef); writing-original draft preparation, A.B. (Amina Bekhoukh), I.M., L.S., and A.B. (Abdelghani Benyoucef); writing-review and editing, all authors; supervision, A.B. (Abdelghani Benyoucef). All authors read and agreed to the published version of the manuscript.

Funding: This research received no external funding.

Data Availability Statement: The data created in this study are fully depicted in the article.

Acknowledgments: The authors would like to thank the Algerian Ministry of Higher Education and Scientific Research for providing the facilities for this work and the Institute of Materials Science at the University of Alicante in Spain for their cooperation.

Conflicts of Interest: The authors declare no conflict of interest.

\section{References}

1. Anbarasan, R.; Ponprapakaran, K.; Subramani, R.H.; Baskaran, R.; Tung, K.-L. Synthesis, characterization and catalytic activity of copolymer/metal oxide nanocomposites. Polym. Bull. 2018, 76, 4117-4138. [CrossRef]

2. Fernandes, S.S.; Castro, M.C.R.; Mesquita, I.; Andrade, L.; Mendes, A.; Raposo, M.M.M. Synthesis and characterization of novel thieno [3,2-b] thiophene based metal-free organic dyes with different heteroaromatic donor moieties as sensitizers for dye-sensitized solar cells. Dye. Pigment. 2017, 136, 46-53. [CrossRef]

3. Günes, S.; Neugebauer, H.; Sariciftci, N.S. Conjugated Polymer-Based Organic Solar Cells. Chem. Rev. 2007, 107, 1324-1338. [CrossRef] [PubMed]

4. Radja, I.; Djelad, H.; Morallon, E.; Benyoucef, A. Characterization and electrochemical properties of conducting nanocomposites synthesized from p-anisidine and aniline with titanium carbide by chemical oxidative method. Synth. Met. 2015, 202, 25-32. [CrossRef]

5. Qi, Y.-N.; Xu, F.; Sun, L.-X.; Zeng, J.-L.; Liu, Y.-Y. Thermal stability and glass transition behavior of PANI/ $\alpha$-Al2O3 composites. J. Therm. Anal. Calorim. 2008, 94, 553-557. [CrossRef]

6. Lazarev, A.N. Vibrational Spectra and Structure of Silicates; Springer: New York, NY, USA, 1995.

7. Rahman, S.U.; Röse, P.; Surati, M.; Shah, A.U.H.A.; Krewer, U.; Bilal, S. 3D Polyaniline Nanofibers Anchored on Carbon Paper for High-Performance and Light-Weight Supercapacitors. Polymers 2020, 12, 2705. [CrossRef]

8. Rahman, S.U.; Röse, P.; Shah, A.U.H.A.; Krewer, U.; Bilal, S.; Farooq, S. Exploring the Functional Properties of Sodium Phytate Doped Polyaniline Nanofibers Modified FTO Electrodes for High-Performance Binder Free Symmetric Supercapacitors. Polymers 2021, 13, 2329. [CrossRef]

9. Cai, G.; Tu, J.; Zhou, D.; Zhang, J.; Xiong, Q.; Zhao, X.; Wang, X.; Gu, C. Multicolor Electrochromic Film Based on TiO2@Polyaniline Core/Shell Nanorod Array. J. Phys. Chem. C 2013, 117, 15967-15975. [CrossRef]

10. Rahman, S.U.; Röse, P.; Shah, A.U.H.A.; Krewer, U.; Bilal, S. An Amazingly Simple, Fast and Green Synthesis Route to Polyaniline Nanofibers for Efficient Energy Storage. Polymers 2020, 12, 2212. [CrossRef]

11. Farooq, S.; Tahir, A.; Krewer, U.; Shah, A.U.H.A.; Bilal, S. Efficient photocatalysis through conductive polymer coated FTO counter electrode in platinum free dye sensitized solar cells. Electrochimica Acta 2019, 320, 134544. [CrossRef]

12. Ullah, R.; Yaseen, S.; Shah, A.-U.-H.A.; Bilal, S.; Kamran, M.; Rahim, M. Anticorrosive polyaniline synthesized using coconut oil as the dispersion medium. Mater. Chem. Phys. 2021, 273, 125071. [CrossRef]

13. Zia, T.U.H.; Shah, A.U.H.A. Understanding the Adsorption of 1 NLB Antibody on Polyaniline Nanotubes as a Function of Zeta Potential and Surface Charge Density for Detection of Hepatitis C Core Antigen: A Label-Free Impedimetric Immunosensor. Colloids Surf. A Physicochem. Eng. Asp. 2021, 626, 127076. [CrossRef]

14. Zhang, Z.; Wan, M. Nanostructures of polyaniline composites containing nano-magnet. Synth. Met. 2003, 132, 205-212. [CrossRef] 
15. He, Y. A novel emulsion route to sub-micrometer polyaniline/nano-ZnO composite fibers. Appl. Surf. Sci. 2005, 249, 1-6. [CrossRef]

16. Wang, S.; Tan, Z.; Li, Y.; Sun, L.; Zhang, T. Synthesis, characterization and thermal analysis of polyaniline $/ \mathrm{ZrO}_{2}$ composites. Thermochim. Acta 2006, 441, 191-194. [CrossRef]

17. Cheng, Q.; Fang, Z.; Yi, X.; An, X.; Tang, B.; Xu, Y. "Ex Situ” Concept for toughening the RTmable BMI matrix composites, part I: Improving the interlaminar fracture toughness. J. Appl. Polym. Sci. 2008, 109, 1625-1634. [CrossRef]

18. Benykhlef, S.; Bekhoukh, A.; Berenguer, R.; Benyoucef, A.; Morallon, E. PANI-derived polymer/Al2O3 nanocomposites: Synthesis, characterization, and electrochemical studies. Colloid Polym. Sci. 2016, 294, 1877-1885. [CrossRef]

19. Yoshimoto, S.; Ohashi, F.; Ohnishi, Y.; Nonami, T. Synthesis of polyaniline-montmorillonite nanocomposites by the mechanochemical intercalation method. Synth. Met. 2004, 145, 265-270. [CrossRef]

20. Dakshayini, B.; Reddy, K.R.; Mishra, A.; Shetti, N.P.; Malode, S.J.; Basu, S.; Naveen, S.; Raghu, A.V. Role of conducting polymer and metal oxide-based hybrids for applications in ampereometric sensors and biosensors. Microchem. J. 2019, 147, 7-24. [CrossRef]

21. Rehman, M.N.U.; Munawar, T.; Nadeem, M.S.; Mukhtar, F.; Maqbool, A.; Riaz, M.; Manzoor, S.; Ashiq, M.N.; Iqbal, F. Facile synthesis and characterization of conducting polymer-metal oxide based core-shell PANI-Pr $\mathrm{P}_{2} \mathrm{O}-\mathrm{NiO}_{-} \mathrm{Co}_{3} \mathrm{O}_{4}$ nanocomposite: As electrode material for supercapacitor. Ceram. Int. 2021, 47, 18497-18509. [CrossRef]

22. Abdah, M.A.A.M.; Azman, N.H.N.; Kulandaivalu, S.; Sulaiman, Y. Review of the use of transition-metal-oxide and conducting polymer-based fibres for high-performance supercapacitors. Mater. Des. 2020, 186, 108199. [CrossRef]

23. Rabbani, G.; Mollah, M.Y.A.; Susan, A.B.H.; Islam, M. In situ electrodeposition of conducting polymer/metal oxide composites on iron electrode for energy storage applications. Mater. Today Proc. 2020, 29, 1192-1198. [CrossRef]

24. Lokhande, V.; Lokhande, C.; Kim, J.H.; Ji, T. Supercapacitive composite metal oxide electrodes formed with carbon, metal oxides and conducting polymers. J. Alloy. Compd. 2016, 682, 381-403. [CrossRef]

25. Benabid, F.Z.; Zouai, F.; Benachour, D. Dielectric properties of some polymers/ metal oxide nanoparticles nanocomposites using fast technique. Rev. Roum. Chim. 2020, 65, 1017-1025. [CrossRef]

26. Tudorache, F.; Grigoraş, M. Study of polyaniline-iron oxides composites using for gas detection. Optoelectron. Adv. Mater. Rapid Commun. 2010, 4, 43-47.

27. Zenasni, M.; Quintero-Jaime, A.; Benyoucef, A.; Benghalem, A. Synthesis and characterization of polymer $/ \mathrm{V}_{2} \mathrm{O}_{5}$ composites based on poly(2-aminodiphenylamine). Polym. Compos. 2021, 42, 1064-1074. [CrossRef]

28. Maaza, L.; Djafri, F.; Belmokhtar, A.; Benyoucef, A. Evaluation of the influence of Al2O3 nanoparticles on the thermal stability and optical and electrochemical properties of PANI-derived matrix reinforced conducting polymer composites. J. Phys. Chem. Solids 2021, 152, 109970. [CrossRef]

29. Kouidri, F.Z.; Moulefera, I.; Bahoussi, S.; Belmokhtar, A.; Benyoucef, A. Development of hybrid materials based on carbon black reinforced poly(2-methoxyaniline): Preparation, characterization and tailoring optical, thermal and electrochemical properties. Colloid Polym. Sci. 2021, 299, 1-9. [CrossRef]

30. Boutaleb, N.; Chouli, F.; Benyoucef, A.; Zeggai, F.Z.; Bachari, K. A comparative study on surfactant c etyltrimethylammoniumbromide modified clay-based poly(p-anisidine) nanocomposites: Synthesis, characterization, optical and electrochemical properties. Polym. Compos. 2021, 42, 1648-1658. [CrossRef]

31. Babazadeh, M.; Zalloi, F.; Olad, A. Fabrication of Conductive Polyaniline Nanocomposites Based on Silica Nanoparticles via In-Situ Chemical Oxidative Polymerization Technique. Synth. React. Inorg. Met. Chem. 2014, 45, 86-91. [CrossRef]

32. Zhang, D.; Li, J.; Zheng, J. Synthesis and electrochemical properties of PANI-TiC nanocomposite and its electrocatalytic behavior. Mater. Lett. 2013, 93, 99-102. [CrossRef]

33. Deshmukh, M.A.; Patil, H.K.; Bodkhe, G.A.; Yasuzawa, M.; Koinkar, P.; Ramanaviciene, A.; Shirsat, M.D.; Ramanavicius, A. EDTAmodified PANI/SWNTs nanocomposite for differential pulse voltammetry based determination of Cu(II) ions. Sens. Actuators B Chem. 2018, 260, 331-338. [CrossRef]

34. Pawar, S.G.; Patil, S.L.; Chougule, M.A.; Mane, A.T.; Jundale, D.M.; Patil, V.B. Synthesis and Characterization of Polyaniline:TiO2Nanocomposites. Int. J. Polym. Mater. 2010, 59, 777-785. [CrossRef]

35. Wang, Y.; Jing, X. Formation of Polyaniline Nanofibers: A Morphological Study. J. Phys. Chem. B 2008, 112, 1157-1162. [CrossRef] [PubMed]

36. Anilkumar, P.; Jayakannan, M. New Renewable Resource Amphiphilic Molecular Design for Size-Controlled and Highly Ordered Polyaniline Nanofibers. Langmuir 2006, 22, 5952-5957. [CrossRef] [PubMed]

37. Zhang, L.; Liu, P.; Su, Z. Preparation of PANI-TiO2 nanocomposites and their solid-phase photocatalytic degradation. Polym. Degrad. Stab. 2006, 91, 2213-2219. [CrossRef]

38. Popov, A.; Brasiunas, B.; Mikoliunaite, L.; Bagdziunas, G.; Ramanavicius, A.; Ramanaviciene, A. Comparative study of polyaniline (PANI), poly(3,4-ethylenedioxythiophene) (PEDOT) and PANI-PEDOT films electrochemically deposited on transparent indium thin oxide based electrodes. Polymers 2019, 172, 133-141. [CrossRef]

39. Wei, Y.; Jang, G.-W.; Hsueh, K.F.; Scherr, E.M.; MacDiarmid, A.G.; Epstein, A.J. Thermal transitions and mechanical properties of films of chemically prepared polyaniline. Polymers 1992, 33, 314-322. [CrossRef]

40. Popov, A.; Brasiunas, B.; Damaskaite, A.; Plikusiene, I.; Ramanavicius, A.; Ramanaviciene, A. Electrodeposited Gold Nanostructures for the Enhancement of Electrochromic Properties of PANI-PEDOT Film Deposited on Transparent Electrode. Polymers 2020, 12, 2778. [CrossRef] 
41. Begum, B.; Bilal, S.; Shah, A.U.H.A.; Röse, P. Physical, Chemical, and Electrochemical Properties of Redox-Responsive Polybenzopyrrole as Electrode Material for Faradaic Energy Storage. Polymers 2021, 13, 2883. [CrossRef]

42. Samain, L.; Jaworski, A.; Edén, M.; Ladd, D.M.; Seo, D.-K.; Garcia-Garcia, F.J.; Häussermann, U. Structural analysis of highly porous $\gamma$-Al2O3. J. Solid State Chem. 2014, 217, 1-8. [CrossRef]

43. Chouli, F.; Radja, I.; Morallon, E.; Benyoucef, A. A novel conducting nanocomposite obtained by p-anisidine and aniline with titanium(IV) oxide nanoparticles: Synthesis, Characterization, and Electrochemical properties. Polym. Compos. 2015, 38, E254-E260. [CrossRef]

44. Deshmukh, M.A.; Gicevicius, M.; Ramanaviciene, A.; Shirsat, M.; Viter, R.; Ramanavicius, A. Hybrid electrochemical/electrochromic $\mathrm{Cu}(\mathrm{II})$ ion sensor prototype based on PANI/ITO-electrode. Sens. Actuators B Chem. 2017, 248, 527-535. [CrossRef]

45. Basnayaka, P.A.; Ram, M.K.; Stefanakos, E.K.; Kumar, A. Supercapacitors based on graphene-polyaniline derivative nanocomposite electrode materials. Electrochim. Acta 2013, 92, 376-382. [CrossRef]

46. Simon, P.; Gogotsi, Y.; Dunn, B. Where Do Batteries End and Supercapacitors Begin? Science 2014, 343, 1210-1211. [CrossRef] [PubMed]

47. Gao, X.; Jing, X.; Li, Y.; Zhu, J.; Zhang, M. Synthesis and characterization of phosphorized polyaniline doped with phytic acid and its anticorrosion properties for Mg-Li alloy. J. Macromol. Sci. Part A 2018, 55, 24-35. [CrossRef] 